\title{
Associations of sleep quality and sleep duration with frailty and pre-frailty in an elderly population Rugao longevity and ageing study
}

Xue-Hui Sun ${ }^{1,2 \dagger}$, Teng $\mathrm{Ma}^{3+}$, Shun Yao ${ }^{1}$, Ze-Kun Chen ${ }^{4}$, Wen-Dong Xü ${ }^{3}$ Xiao-Yan Jiang ${ }^{4^{*}}$ and Xiao-Feng Wang ${ }^{1,2,3,5,6^{*}}$ (D)

\begin{abstract}
Background: Previous studies suggest that poor sleep quality or abnormal sleep duration may be associated with frailty. Here we test the associations of sleep disturbances with both frailty and pre-frailty in an elderly population.

Methods: Participants included 1726 community-dwelling elders aged 70-87 years. Pittsburgh Sleep Quality Index (PSQI) was used to assess sleep disturbances. Frailty was defined using phenotype criteria. Logistic regression models were used to estimate odds ratio of the associations.

Results: The average PSQI score was 5.4 (SD, 3.1). Overall 43.6\% of the participants had poor sleep quality (PSQl> 5), $8.2 \%$ had night sleep time $\leq 5 \mathrm{~h}$, and $27.8 \%$ had night sleep time $\geq 9 \mathrm{~h}$. The prevalence of frailty and pre-frailty was 9.2 and $52.8 \%$, respectively. The proportions of PSQI> 5 increased with the severity of frailty status (robust: pre-frail: frail, 34.5\%: 48\%: 56.1\%, $P<0.001$ ). After adjustment for multiple potential confounders, poor sleep quality (PSQl> 5) was associated with higher odds of frailty $(\mathrm{OR}=1.78,95 \% \mathrm{Cl} 1.19-2.66)$ and pre-frailty $(\mathrm{OR}=1.51,95 \% \mathrm{Cl} 1.20-1.90)$. Sleep latency, sleep disturbance, and daytime dysfunction components of PSQI measurements were also associated with frailty and pre-frailty. In addition, sleep time $9 \mathrm{~h}$ /night was associated with higher odds of frailty and pre-frailty.

Conclusions: We provided preliminary evidences that poor sleep quality and prolonged sleep duration were associated with being frailty and pre-frailty in an elderly population aged $70-87$ years. The associations need to be validated in other elderly populations.
\end{abstract}

Keywords: Frailty, Sleep disturbances, Sleep quality, Sleep duration, Elderly population

\section{Background}

Frailty is a clinical syndrome characterized by loss of physiologic reserve and resistance to stressors due to $\mathrm{cu}-$ mulative declines across multiple physiologic systems. Frailty results in vulnerability to adverse outcomes including restricted mobility, reduced self-reliance and disability, falls, hospitalization, and mortality [1-3]. Frailty is a public health problem with a prevalence of about

\footnotetext{
* Correspondence: xiaoyanjiang001@163.com; xiaofengwang71@163.com ${ }^{+}$Xue-Hui Sun and Teng Ma contributed equally to this work.

${ }^{4}$ Key Laboratory of Arrhythmias of the Ministry of Education of China, Tongji University School of Medicine, Shanghai 200092, People's Republic of China ${ }^{1}$ Ministry of Education Key Laboratory of Contemporary Anthropology, School of Life Sciences, Fudan University, Shanghai, China

Full list of author information is available at the end of the article
}

$10 \%$ in the community-dwelling elderly population [4]. However, frailty and pre-frailty are reversible conditions if appropriately treated. Therefore, identifying high risk elders of frailty for specific management of underlining causes is important to prevent from developing to more advanced condition, such as disability. Several risk factors of frailty had been proposed and some had been validated, such as age, low socioeconomic status, cognitive impairment, and diabetes $[5,6]$.

Sleep disturbances are common and serious problems of the elderly population $[7,8]$. About $50 \%$ of the elderly people suffers from sleep problems [7]. Sleep is extremely important to health since human body carries out a series of biological and physiological activities 
during sleep process, such as hormonal release, energy metabolism, glucose and cardiovascular regulation, and self-regulation and recovery of physiological functions [9]. Sleep disorders were found to be associated with increased risks of different adverse outcomes, such as obesity, hypertension, cognitive impairment, depression, and death [10-14].

Recently, poor sleep quality was reported to be associated with prevalent $[15,16]$ and incident frailty at followup in U.S. community-dwelling elders [17]. In addition, an U-shaped sleep duration-frailty association $[17,18]$ or prolonged sleep duration-frailty relationship $[19,20]$ was also reported to community dwellers. However, more evidences need to be accumulated before sleep disturbances established as a behavior risk factors of frailty.

In this study, we aimed to investigate the associations of different symptoms of sleep disturbance (poor sleep quality, several components of sleep quality, prolonged and insufficient sleep duration) with frailty in a community-dwelling population aged $70-87$ years.

\section{Methods}

\section{Study design and participants}

We used data of the ageing arm of the Rugao Longevity and Ageing Study (RuLAS), a population-based observational two-arm cohort study conducted in Rugao, a typical, medium-sized city of Jiangsu province, China. The ageing arm of RuLAS is a longitudinal cohort followed-up every 1.5 years. A detailed description of this study was provided elsewhere [21]. Briefly, we recruited 1788 elders from 31 rural communities of Jiang'an Township of Rugao city between in Nov-Dec. 2014 (wave1) according to 5-year age and sex strata. From Apri. 2016 through Jun. 2016, we conducted the second-wave examination of the ageing arm, excluding 297 subjects (55 died and 242 did not come) and including an additional 333 subjects. Among the participants in the second wave, 1726 subjects aged 70-87 years with complete data on sleep and frailty variables were included in the present study. During the fieldwork, all participants were taken a fasting blood sample drawn. Then they participated in a face-to-face interview and physical examination. All of them answered a structured questionnaire themselves. This study was approved by the Human Ethics Committee of the School of Life Sciences of Fudan University, Shanghai, China. Written informed consents were obtained from all the participants.

\section{Sleep measurements}

The participants finished the Pittsburgh Sleep Quality Index (PSQI) at wave 2 survey.The PSQI questionnaire consists of 19 items which include components of sleep quality, sleep latency, sleep duration, sleep efficiency, sleep disturbances, sleep medication use, and daytime dysfunction [22]. Each component is coded on a 4-point scale (0-3), with high scores reflecting more sleep symptoms. The Chinese version of the PSQI have good overall reliability $(r=0.82-0.83)$ and test-retest reliability $(r=0.77-0.85)$ in community adults with primary insomnia [23]. Global scores provide an assessment of overall sleep quality which ranges from 0 to 21 , with scores of $>5$ indicating poor sleep quality [23].

\section{Frailty measurements}

The widely used Fried's phenotype criterion includes unintentional weight loss, weakness, exhaustion, slowness, and low activity components [24]. We used a similar definition to measure frailty phenotype $[25,26]$. In brief, unintentional weight loss, exhaustion, and low activity were measured with self-reported items "weight has decreased by $4.5 \mathrm{~kg}$ or $5 \%$ during the last 12 months", "energetic most of the time or feeling tired all of the time (at least 3 or 4 days a week)", and "needing help to walk", respectively. Slowness was defined as being below the 20th sex-specific percentile in gait speeds measured with a timed 'up and go' (TUG) test (the time stand up from an armchair, walk $3 \mathrm{~m}$, return, and sit down again). Weakness was defined as being below the 20th sexspecific percentile in maximum handgrip strength. Grip strength in kilograms was measured using a dynamometer (Shanghai Wanqing Rlrctron Co. Ltd., Shanghai, China) for three attempts of each hand. The max value of two hands was used in this study. Participants with any three or more indicators is defined as "frail", any one or two is pre-frail, and zero is"non-frail".

\section{Covariates}

Covariates included age (70-74 years, $75-79$ years, $80-$ 84 years, $85+$ years), gender (men; women), occupation (farmers, others), marital status (currently married, others), education level (illiterate; literate), smoking (none; ever, current smoker), drinking status (none, ever, current drinker), perceived overall health status (good, poor), and body mass index (BMI, $<24 \mathrm{~kg} / \mathrm{m}^{2}, 24$ to $27.9 \mathrm{~kg} / \mathrm{m}^{2}$, or $\geq 28 \mathrm{~kg} / \mathrm{m}^{2}$ ) [27]. Diabetes was defined as having a diabetic history, on any anti-diabetic agent, or a fasting plasma glucose level of $>7.0 \mathrm{mmol} / \mathrm{L}$.

Hypertension was defined as having a hypertension history, or a mean blood pressure higher than 140/90 $\mathrm{mmHg}$, or on any antihypertensive agent. The Hasegawa Dementia Scale-Revised (HDS-R), including 11 items to measure orientation, memory, attention/calculation and verbal fluency, is a widely used brief and reliable measurement for evaluating global cognitive function [28, 29]. The presence of mild cognitive impairment (MCI) was defined by a HDS-R of $\leq 21.5$ [30]. 


\section{Statistical analysis}

Descriptive statistics were used as percentages or mean \pm standard deviation (SD). The Chi-square test was used for comparison of categorical variables among frail groups. Logistic regression models were used to estimate odds ratios and 95\% confidence intervals for the associations of sleep variables with frailty. Potential confounding factors adjusted including age, gender, occupation, marital status, education level, smoking status, drinking status, BMI category, hypertension, diabetes, $\mathrm{MCI}$, and perceived overall health. Statistical analyses were performed with IBM SPSS 19.0 (IBM Corporation, Armonk, NY, USA). A two-sided $p<0.05$ was considered significant.

\section{Results}

\section{Characteristics of the study population}

The average PSQI score of the studied elderly population (aged 77.6 \pm 3.9 years) was 5.4 (SD, 3.1) and the average night sleep time $7.6 \mathrm{~h}$ (SD, $1.7 \mathrm{~h}$ ). Overall 43.6\% of the elderly adults had poor sleep quality (PSQI $>5$ ), $8.2 \%$ had night sleep time $\leq 5 \mathrm{~h}$, and $27.8 \%$ had night sleep time $\geq 9 \mathrm{~h}$. The prevalence of frailty and pre-frailty was 9.2 and $52.8 \%$, respectively. The percentages of female, illiterate, uncoupling, diabetes, MCI decreased from robust to pre-frail, then to frailty groups while the percentages of smokers and alcohol drinkers increased $(p<0.05)$ (Table 1).

\section{Associations of sleep quality with frailty}

The proportions of participants with poor sleep quality (PSQI $>5$ ) increased with the severity of frailty in the elderly (robust: pre-frail: frail, 34.5\%: 48\%: 56.1\%, $P<0.001$ ) (Table 2).

After adjustment for multiple potential confounders including age group, gender, occupation, education, smoking, drinking, BMI category, diabetes, hypertension, $\mathrm{MCI}$, and perceived overall health status, poor sleep quality (PSQI> 5) was associated with higher odds of being frailty $(\mathrm{OR}=1.78,95 \%$ CI 1.19-2.66). With 1 point increments in PSQI score, the odds ratio of frailty increased by $16 \%$ $(\mathrm{OR}=1.16,95 \% \mathrm{CI}(1.09-1.23)$. Poor sleep quality defined by $\mathrm{PSQI}>5$ was also significantly associated with the odds of pre-frailty compared with the robust participants independent of other factors pre-frailty $(\mathrm{OR}=1.51,95 \% \mathrm{CI}$ 1.20-1.90). With per SD increments in PSQI score, the multivariable-adjusted odds of pre-frailty increased by $11 \%, \mathrm{OR}=1.11,95 \%$ CI (1.04-1.13) (Table 3). In addition, using PSQI> 6 as cut-point [23], we also found significant associations of poor sleep quality with increased odds of pre-frailty and frailty (data not shown).

\section{Associations of sleep quality component with frailty}

For components of PSQI, on the whole, higher percentages of sleep symptoms were found in sleep quality component, sleep latency component, sleep duration component, sleep efficiency component, sleep disturbance component, and daytime dysfunction component from robust group to pre-frail group, and then to frail group (Table 2). After adjustments for multiple covariates, sleep latency, sleep disturbance, and daytime dysfunction components were significantly associated with higher odds of pre-frailty and frailty (Table 3).

\section{Associations of sleep duration with frailty}

Table 4 showed the associations between reported sleep duration and frailty. The odds of being frail in those with a sleep time $\leq 5 \mathrm{~h}$ per night was significantly increased compared to those with a sleep time $7-8 \mathrm{~h}$. However, the OR attenuated with the addition of adjustment variables and was not statistically significant after adjustment for sleep quality.

Long sleep duration of $\geq 9 \mathrm{~h}$, compared with sleep 7-8 $\mathrm{h}$, was associated with increased risk of pre-frailty $(\mathrm{OR}=$ $1.82,95 \% \mathrm{CI} 1.37-2.42)$ and frailty $(\mathrm{OR}=2.98,95 \% \mathrm{CI}$ 1.95-4.56), and the correlation was not affected by other factors such as sleep quality (Table 4).

\section{Discussion}

In the present study, we found that poor sleep quality, long sleep latency, sleep disturbance, daytime dysfunction, and longed sleep duration were associated with increased odds of frailty in an elderly population. In addition, to the best of our knowledge, for the first time, we found that sleep disturbance variables such as sleep latency, were associated pre-frailty in this elderly population aged $70-87$ years.

In the Osteoporotic Fractures in Men (MrOS) cohort of U.S. males aged 67 years and older, Ensrud [15] et al. found that poor subjective sleep quality of $\mathrm{PSQI}>5$, objective parameters of less sleep efficiency, and objective parameters of sleep disordered breathing were independently associated with a higher odd of being frail in cross-sectional analysis. Later, in a prospective study follow-up of an average of 3.4 years, they replicated these associations [17]. Our results are similar to their observations that poor subjective sleep quality was associated with frailty status in Rugao population. In addition, we extended the associations to pre-frailty status which is even more clinically relevant since it is reversible condition when timely intervened.

Poor sleep quality measured by PSQI was associated with frailty not only in community population setting but also in institutionalized setting where frail elderly (374 elderly residents of long-stay institutions aged $77.52 \pm 7.82$ years) exhibited poor sleep quality [31]. In addition, the associations were also observed for frailty measured with other instruments. In 351 Atahualpa residents aged $\geq 60$ years, Brutto et al. found that higher 
Table 1 Demographic characteristics of participants by frailty status

\begin{tabular}{|c|c|c|c|c|c|}
\hline characteristics & All $(n=1726)$ & Robust $(n=656)$ & Pre-frail $(n=911)$ & Frail $(n=159)$ & $P_{\text {_value }}$ \\
\hline \multicolumn{5}{|l|}{ Age groups (years) } & \multirow[t]{5}{*}{$<0.001$} \\
\hline $70-74$ & $427(24.7)$ & $204(31.1)$ & $204(22.4)$ & 19 (11.9) & \\
\hline $75-79$ & $773(44.8)$ & $314(47.9)$ & $402(44.1)$ & $57(35.8)$ & \\
\hline $80-84$ & $415(24)$ & $120(18.3)$ & $235(25.8)$ & $60(37.7)$ & \\
\hline $85^{+}$ & $111(6.4)$ & $18(2.7)$ & $70(7.7)$ & $23(14.5)$ & \\
\hline \multicolumn{5}{|l|}{ Gender } & \multirow[t]{3}{*}{$<0.001$} \\
\hline Male & $816(47.3)$ & $385(58.7)$ & $382(42)$ & 49 (30.8) & \\
\hline Female & $909(52.7)$ & $271(41.3)$ & $528(58)$ & $110(69.2)$ & \\
\hline \multicolumn{5}{|l|}{ Occupation } & \multirow[t]{3}{*}{0.032} \\
\hline Farmer & $1502(88.6)$ & $566(87.6)$ & $790(88.6)$ & $146(93)$ & \\
\hline Other & $193(11.4)$ & $80(12.4)$ & $102(11.4)$ & $11(7)$ & \\
\hline \multicolumn{5}{|l|}{ Education } & \multirow[t]{3}{*}{$<0.001$} \\
\hline Illiterate & $885(51.6)$ & $260(39.9)$ & $515(57)$ & $110(69.2)$ & \\
\hline Literate & $829(48.4)$ & $391(60.1)$ & $389(43)$ & 49 (30.8) & \\
\hline \multicolumn{5}{|l|}{ Marital status } & \multirow[t]{3}{*}{$<0.001$} \\
\hline Current marital & $1126(66)$ & $459(70.8)$ & $585(65)$ & $82(52.2)$ & \\
\hline Other & $579(34)$ & $189(29.2)$ & $315(35)$ & $75(47.8)$ & \\
\hline \multicolumn{5}{|l|}{ Smoking } & \multirow[t]{4}{*}{$<0.001$} \\
\hline None & $1251(73.7)$ & $427(65.8)$ & $696(77.9)$ & $128(82.1)$ & \\
\hline Smoker & $301(17.7)$ & $159(24.5)$ & $123(13.8)$ & $19(12.2)$ & \\
\hline Ever & $146(8.6)$ & $63(9.7)$ & $74(8.3)$ & $9(5.8)$ & \\
\hline \multicolumn{5}{|l|}{ Drinking } & \multirow[t]{4}{*}{$<0.001$} \\
\hline None & $1098(65.1)$ & $364(56.7)$ & $617(69.1)$ & $117(76.5)$ & \\
\hline Drinker & $443(26.2)$ & $218(34)$ & $199(22.3)$ & $26(17)$ & \\
\hline Ever & $147(8.7)$ & $60(9.4)$ & $77(8.6)$ & $10(6.5)$ & \\
\hline \multicolumn{5}{|l|}{ BMI category } & \multirow[t]{4}{*}{0.163} \\
\hline$<24$ & $931(54.9)$ & $334(51.9)$ & $509(56.8)$ & $88(56.1)$ & \\
\hline $24-27.9$ & $574(33.8)$ & $240(37.3)$ & $291(32.5)$ & $43(27.4)$ & \\
\hline$\geq 28$ & $192(11.3)$ & $70(10.9)$ & $96(10.7)$ & 26 (16.6) & \\
\hline \multicolumn{5}{|c|}{ Perceived overall health status } & \multirow[t]{3}{*}{0.448} \\
\hline Good & $1432(83.6)$ & $600(92)$ & $738(81.6)$ & $94(59.5)$ & \\
\hline Poor & $282(16.5)$ & $52(8)$ & $166(18.4)$ & $64(40.5)$ & \\
\hline \multicolumn{5}{|l|}{ Hypertension } & \multirow[t]{3}{*}{0.171} \\
\hline No & $436(25.5)$ & $176(27.2)$ & $221(24.4)$ & $39(24.5)$ & \\
\hline Yes & $1277(74.6)$ & $472(72.8)$ & $685(75.6)$ & $120(75.5)$ & \\
\hline \multicolumn{5}{|l|}{ Diabetes } & \multirow[t]{3}{*}{$<0.001$} \\
\hline No & $1401(82.3)$ & $545(84.4)$ & $734(81.3)$ & $122(79.2)$ & \\
\hline Yes & $302(17.7)$ & $101(15.6)$ & $169(18.7)$ & $32(20.8)$ & \\
\hline \multicolumn{5}{|l|}{$\mathrm{MCl}$} & \multirow[t]{3}{*}{$<0.001$} \\
\hline No & $889(51.7)$ & $438(67)$ & $408(44.8)$ & $43(27.4)$ & \\
\hline Yes & $832(48.3)$ & $216(33)$ & $502(55.2)$ & $114(72.6)$ & \\
\hline
\end{tabular}


Table 2 Distribution and comparison of the PSQI scores among robust, pre-frail and frail groups

\begin{tabular}{|c|c|c|c|c|}
\hline Sleep variables & Robust(656) & Pre-frail(911) & Frail(157) & $P$ \\
\hline Poor subjective sleep quality & & & & $<0.001$ \\
\hline Total score $\leq 5$ & $430(65.5)$ & $473(52)$ & 69 (43.9) & \\
\hline Total score $>5$ & $226(34.5)$ & $436(48)$ & $88(56.1)$ & \\
\hline Sleep quality component & & & & $<0.001$ \\
\hline 0 & $155(23.7)$ & $212(23.5)$ & $25(15.9)$ & \\
\hline 1 & $427(65.4)$ & $524(58)$ & $95(60.5)$ & \\
\hline 2 & $64(9.8)$ & $156(17.3)$ & $33(21)$ & \\
\hline 3 & $7(1.1)$ & $12(1.3)$ & $4(2.5)$ & \\
\hline Sleep latency component & & & & $<0.001$ \\
\hline 0 & $231(36.9)$ & $234(27.4)$ & $40(27.6)$ & \\
\hline 1 & $276(44.1)$ & $396(46.4)$ & $50(34.5)$ & \\
\hline 2 & $81(12.9)$ & $137(16)$ & $30(20.7)$ & \\
\hline 3 & $38(6.1)$ & $87(10.2)$ & $25(17.2)$ & \\
\hline Sleep duration component & & & & 0.021 \\
\hline 0 & $342(53.3)$ & $482(54.2)$ & $90(59.6)$ & \\
\hline 1 & $244(38)$ & $329(37)$ & $37(24.5)$ & \\
\hline 2 & $31(4.8)$ & $46(5.2)$ & $13(8.6)$ & \\
\hline 3 & $25(3.9)$ & $33(3.7)$ & $11(7.3)$ & \\
\hline Sleep efficiency component & & & & 0.002 \\
\hline 0 & $322(50.5)$ & $409(47.3)$ & 65 (43.6) & \\
\hline 1 & $129(20.2)$ & $149(17.2)$ & $23(15.4)$ & \\
\hline 2 & $76(11.9)$ & $123(14.2)$ & $13(8.7)$ & \\
\hline 3 & $111(17.4)$ & $184(21.3)$ & $48(32.2)$ & \\
\hline Sleep disturbances component & & & & $<0.001$ \\
\hline 0 & $31(4.7)$ & $24(2.6)$ & $2(1.3)$ & \\
\hline 1 & $531(80.9)$ & $640(70.3)$ & $102(65)$ & \\
\hline 2 & $93(14.2)$ & $242(26.6)$ & $51(32.5)$ & \\
\hline 3 & $1(0.2)$ & $4(0.4)$ & $2(1.3)$ & \\
\hline Sleep medication use component & & & & 0.147 \\
\hline 0 & $643(98.8)$ & $888(98.4)$ & $149(96.8)$ & \\
\hline 1 & $2(0.3)$ & $1(0.1)$ & $2(1.3)$ & \\
\hline 2 & $4(0.6)$ & $5(0.6)$ & $2(1.3)$ & \\
\hline 3 & $2(0.3)$ & $8(0.9)$ & $1(0.6)$ & \\
\hline Daytime dysfunction component & & & & $<0.001$ \\
\hline 0 & $465(71.6)$ & $469(51.8)$ & $54(34.4)$ & \\
\hline 1 & $120(18.5)$ & $176(19.4)$ & $40(25.5)$ & \\
\hline 2 & $59(9.1)$ & $203(22.4)$ & 37 (23.6) & \\
\hline 3 & $5(0.8)$ & $57(6.3)$ & 26 (16.6) & - \\
\hline
\end{tabular}

scores of the PSQI were significantly associated with higher scores in the Edmonton Frail Scale [16].

For the component of sleep quality, we found that long sleep latency and sleep disturbances were associated with increased risks of pre-frailty and frailty in Rugao population. This is similar to the observations that long sleep latency and poor sleep efficiency measured by objective actigraph were associated with higher odds of prevalent frailty [15] and higher risk of incident frailty [17]. Another significant component associated with frailty we observed in this population aged 70-87 years is daytime dysfunction. To the best of our 
Table 3 Associations between sleep quality and components of sleep quality and frailty status by logistic regression analysis

\begin{tabular}{|c|c|c|c|c|}
\hline Sleep quality & Crude model & Model1 & Model2 & Model3 \\
\hline \multicolumn{5}{|l|}{ Pre-frail } \\
\hline Poor subjective sleep quality & $1.75(1.43-2.16)^{* * *}$ & $1.61(1.3-1.99)^{* * *}$ & $1.63(1.3-2.04)^{* * *}$ & $1.51(1.20-1.90)^{* * *}$ \\
\hline \multicolumn{5}{|l|}{$\mathrm{PSQ} \mid>5$ vs. $\leq 5$} \\
\hline PSQl global score & $1.11(1.08-1.15)^{* * *}$ & $1.1(1.06-1.14)^{* * *}$ & $1.1(1.06-1.14)^{* * *}$ & $1.08(1.04-1.13)^{* * *}$ \\
\hline Per SD PSQI score & $1.41(1.26-1.57)^{* * *}$ & $1.35(1.21-1.52)^{* * *}$ & $1.35(1.2-1.52)^{* * *}$ & $1.29(1.14-1.46)^{* * *}$ \\
\hline Sleep quality component & $1.22(1.04-1.42)^{*}$ & $1.15(0.98-1.36)$ & $1.15(0.97-1.37)$ & $1.08(0.91-1.29)$ \\
\hline Sleep latency component & $1.3(1.16-1.46)^{* * *}$ & $1.24(1.1-1.4)^{* * *}$ & $1.24(1.1-1.41)^{* *}$ & $1.23(1.08-1.4)^{* *}$ \\
\hline Sleep duration component & $0.98(0.86-1.12)$ & $0.95(0.83-1.09)$ & $0.93(0.8-1.07)$ & $0.9(0.78-1.05)$ \\
\hline Sleep efficiency component & $1.1(1.01-1.2)^{*}$ & $1.05(0.96-1.15)$ & $1.05(0.96-1.16)$ & $1.01(0.92-1.12)$ \\
\hline Sleep disturbance component & $2.01(1.6-2.51)^{* * *}$ & $1.97(1.57-2.48)^{* * *}$ & $2.04(1.6-2.59)^{* * *}$ & $1.88(1.46-2.4)^{* * *}$ \\
\hline Sleep medication use component & $1.21(0.82-1.77)$ & $1.17(0.79-1.73)$ & $1.01(0.67-1.52)$ & $1.01(0.65-1.56)$ \\
\hline Daytime dysfunction component & $1.85(1.62-2.1)^{* * *}$ & $1.9(1.66-2.17)^{* * *}$ & $1.9(1.65-2.19)^{* * *}$ & $1.9(1.64-2.2)^{* * *}$ \\
\hline \multicolumn{5}{|l|}{ Frail } \\
\hline Poor subjective sleep quality & $2.43(1.7-3.46)^{* * *}$ & $2.15(1.49-3.09)^{* * *}$ & $2.19(1.49-3.21)^{* * *}$ & $1.78(1.19-2.66)^{* *}$ \\
\hline \multicolumn{5}{|l|}{ PSQl> 5 vs. $\leq 5$} \\
\hline PSQl global score & $1.22(1.16-1.29)^{* * *}$ & $1.2(1.14-1.27)^{* * *}$ & $1.2(1.13-1.27)^{* * *}$ & $1.16(1.09-1.23)^{* * *}$ \\
\hline Per SD PSQI score & $1.87(1.58-2.21)^{* * *}$ & $1.77(1.49-2.11)^{* * *}$ & $1.75(1.46-2.1)^{* * *}$ & $1.6(1.32-1.94)^{* * *}$ \\
\hline Sleep quality component & $1.66(1.28-2.16)^{* * *}$ & $1.54(1.17-2.01)^{* *}$ & $1.51(1.14-2)^{* *}$ & $1.24(0.92-1.68)$ \\
\hline Sleep latency component & $1.6(1.32-1.93)^{* * *}$ & $1.5(1.23-1.83)^{* * *}$ & $1.45(1.18-1.79)^{* * *}$ & $1.39(1.12-1.72)^{* *}$ \\
\hline Sleep duration component & $1.07(0.86-1.34)$ & $1.02(0.81-1.27)$ & $1.02(0.8-1.28)$ & $0.95(0.74-1.23)$ \\
\hline Sleep efficiency component & $1.25(1.08-1.45)^{* *}$ & $1.16(1-1.34)$ & $1.16(0.99-1.35)$ & $1.08(0.91-1.27)$ \\
\hline Sleep disturbance component & $2.84(1.99-4.05)^{* * *}$ & $2.84(1.97-4.1)^{* * *}$ & $2.85(1.94-4.19)^{* * *}$ & $2.34(1.55-3.51)^{* * *}$ \\
\hline Sleep medication use component & $1.43(0.85-2.41)$ & $1.34(0.78-2.29)$ & $1.21(0.68-2.17)$ & $1.16(0.62-2.19)$ \\
\hline Daytime dysfunction component & $2.67(2.22-3.22)^{* * *}$ & $2.85(2.34-3.46)^{* * *}$ & $2.9(2.36-3.55)^{* * *}$ & $2.8(2.25-3.48)^{* * *}$ \\
\hline
\end{tabular}

Model1 adjusted for age, and gender on crude model. Model2 adjusted for smoking, drinking, education, marital status, occupation, BMI category plus the variables in Model1. Model3 adjusted for diabetes, hypertension, $\mathrm{MCl}$, perceived overall health plus the variables in Model 2

${ }^{*} P<0.05,{ }^{* * P}<0.01,{ }^{* * * P}<0.001$

Table 4 Associations between sleep duration and frailty status by logistic regression analysis

\begin{tabular}{lllll}
\hline $\begin{array}{l}\text { Sleep duration } \\
\text { (h per 24-h period) }\end{array}$ & Crude model & Model 1 & Model 2 & Model 3 \\
\hline $\begin{array}{l}\text { Pre-frail } \\
\leq 5(n=137)\end{array}$ & $0.9(0.58-1.4)$ & $1.04(0.68-1.6)$ & $1.11(0.74-1.68)$ & $1.31(0.87-1.95)$ \\
$5-7(n=360)$ & $1.29(0.97-1.73)$ & $1.33(1-1.77)$ & $1.3(1-1.71)$ & $1.36(1.04-1.77)^{*}$ \\
$7-8(n=712)$ & 1 & 1 & 1 & 1 \\
$\geq 9(n=466)$ & $1.82(1.37-2.42)^{* * *}$ & $1.86(1.41-2.45)^{* * *}$ & $1.84(1.41-2.4)^{* * *}$ & $1.96(1.51-2.53)^{* * *}$ \\
Frail & & & & $1.95(1.01-3.77)^{*}$ \\
$\leq 5(n=137)$ & $2.93(1.63-5.27)^{* * *}$ & $2.04(1.09-3.81)^{*}$ & $0.75(0.4-1.38)$ & $1.77(0.84-3.73)$ \\
$5-7(n=360)$ & $0.78(0.43-1.39)$ & $0.69(0.38-1.27)$ & 1 & $0.64(0.32-1.27)$ \\
$7-8(n=712)$ & 1 & 1 & $2.43(1.51-3.91)^{* * *}$ & 1 \\
$\geq 9(n=466)$ & $2.98(1.95-4.56)^{* * *}$ & $2.4(1.53-3.77)^{* * *}$ & $2.55(1.49-4.35)^{* *}$ \\
\hline
\end{tabular}

Model1 adjusted for age, and gender on crude model. Model2 adjusted for smoking, drinking, education, marital status, occupation, BMI category, diabetes, hypertension, $\mathrm{MCl}$, perceived overall health plus the variables in Model 1 . Model 3 further added sleep quality (P PSQI>5 vs. $\leq 5$ ) to model 2 ${ }^{*} P<0.05,{ }^{* *} P<0.01,{ }^{* * *} P<0.001$ 
knowledge, this is the first report correlated daytime dysfunction with frailty status in elderly population since other studies such as Ensrud et al. $[15,17]$ did not specially analyze the relationship between PSQI components and frailty. However, using the objective actigraph measurements, Ensrud et al. found that another relevant symptoms, excessive daytime sleepiness, were associated with increased odds of frailty in the MrOS cohort [15]. This corroborates our observations from another perspective.

The observations addressing the relationship between sleep duration and frailty were less consistent. Both long sleep duration $(\geq 9 \mathrm{~h})$ and short sleep duration $(\leq 6 \mathrm{~h}$ or $\leq$ $5 \mathrm{~h}$ ) were associated with higher odds of frailty in Japanese [18] and Danish population [32]. However, only long sleep duration $(\geq 10 \mathrm{~h}$ or $\geq 9 \mathrm{~h}$ or $\geq 8 \mathrm{~h}$ ) was found associated with higher odds of frailty in American elderly [19], our Chinese elderly, or Korean elderly people [20], respectively. Interestingly, using data of NHANES cohort of U.S. population, Zhang et al. found that sleeping $>9 \mathrm{~h}$ was associated with frailty in males and sleeping $<6 \mathrm{~h}$ were associated with frailty in females, which indicate a gender specific association [33]. Low levels of daily exercise, low muscle strength, and very slow walking speeds, all indicative of prefrailty/frailty also showed prolonged sleep duration $(\geq 9 \mathrm{~h})$ in a British elderly population [34]. Since both prolonged sleeping hours and frailty may be manifestations or biomarkers of disease status of the studied participant, in the present study, we adjusted several health variables in the analysis models and still observed the associations. In addition, since elderly people may spend more time in bed when they are frail (i.e. reverse causality), and aforementioned cross-sectional data cannot provide evidence for the direction of the association, evidences in the prospective studies need to be accumulated with respect to the association between sleep duration and frailty.

Several possible underline mechanisms may help explain the associations of sleep disturbances with frailty. (1) sleep symptoms may be markers for comorbidities and poor health which increases the likelihood of frailty [17]. Although we adjusted multiple disease covariates in the present study, we could not exclude this possibility. (2) The disrupted circadian rhythms induced by sleep disorder may contribute to dysregulation of immune system with increased systemic inflammation factors which contribute to the development of frailty [35]. (3) sleep disorder may contribute to increased oxidative stress and alterations of metabolic pathways favoring catabolism, which could serve as a combined risk for the development of frailty [36]. (4) Disturbed sleep may reduce growth hormone, insulin-like growth factor-1, and sex hormone such as testosterone secretion, which in turn enhance muscle proteolysis, thus, leading to sarcopenia and frailty [37]. In the future study, we need to measure these cytokines in our participants to explore whether they mediate the sleep-frailty associations.

The limitations of this study need to be mentioned. The cross-sectional nature of this study prohibits causal inference since the relationship between frailty and sleep disturbances may be bidirectional. In addition, it's a pity that we did not measure the actigraphic or polysomnographic parameters in our cohort, therefore, we could not validate the objective associations of sleep disturbances and sleep disordered breathing with frailty. Further, a significantly large percentage of the subjects were farmers, such a specific occupation is not only physically demanding that could impact frailty but also have a particularly unique regimental challenges to one's sleep. This may affect the generalizability of our findings.

\section{Conclusions}

In summary, we found that poor subjective sleep quality, some sleep symptoms measured by PSQI, and prolonged sleep duration were associated with higher odds of frailty, and even pre-frailty in an elderly population aged 70-84 years However, since the associations were crosssectional, the effects of sleep disturbances on frailty incidences need to be validated in the prospective cohort studies of the elderly population of this age group.

\section{Declarations}

Abbreviations

BMI: Body mass index; CRP: C reactive protein; DBP: Diastolic blood pressure; HDS: Hasegawa Dementia Scale; HDS-R: Hasegawa Dementia Scale-Revised: MCI: Mild cognitive impairment; MrOS: Osteoporotic Fractures in Men; NHANES: The National Health and Nutrition Examination Survey; OR: Odds ratio; PSQI: Pittsburgh Sleep Quality Index; RuLAS: Rugao Longevity and Ageing Study; SBP: Systolic blood pressure; TUG: Up and go

\section{Ethics approval and consent to participate}

All procedures performed in studies involving human participants were in accordance with the ethical standards of the institutional and/or national research committee (This study was approved by the Human Ethics Committee of the School of Life Sciences of Fudan University, Shanghai, China.) and with the 1964 Helsinki declaration and its later amendments or comparable ethical standards. Written consents were obtained from all participants prior to participation.

\section{Consent for publication}

Not applicable.

\section{Availability of data and materials}

The datasets used and/or analysed during the current study are available from the corresponding author on reasonable request.

\section{Competing interests}

The authors declare that they have no competing interests.

\section{Funding}

This work was financially supported by grants from the National Key R\&D Program of China (2018YFC2002000,2018YFC2000400), the National Natural Science Foundation of China $(81571372,81670465,81600577)$. The funders have no role in the study design, the collection, analysis, and interpretation of data, in the writing of this manuscript, and in the decision to submit it for publication. 


\section{Author's contribution}

$\mathrm{XH}$ Sun and T Ma were responsible for managing the participant database and retrieving follow-up information; they also contributed to article preparation, in the analyses of data and in drafting the article. S Yao, ZK Chen, and WD Xu supervised the ongoing research, taking part in the initiation of the study and contributing to article preparation. XH Sun,T Ma and XY Jiang contributed to analyses of data and in article preparation. XY Jiang and XF Wang conceived the study, participated in its design and coordination, and helped draft the article. All authors read and approved the final article.

\section{Acknowledgments}

We acknowledge all participants involved in the present study.

\section{Author details}

${ }^{1}$ Ministry of Education Key Laboratory of Contemporary Anthropology, School of Life Sciences, Fudan University, Shanghai, China. ${ }^{2}$ Human Phenome Institute, Fudan University, Shanghai, China. ${ }^{3}$ National Clinical Research Center for Aging and Medicine, Huashan Hospital, Fudan University, Shanghai, China. ${ }^{4}$ Key Laboratory of Arrhythmias of the Ministry of Education of China, Tongji University School of Medicine, Shanghai 200092, People's Republic of China. ${ }^{5}$ Shanghai Key Laboratory of Clinical Geriatric Medicine and Huadong Hospital Clinical Research Center for Geriatric Medicine, Shanghai, China. ${ }^{6}$ Unit of epidemiology, Human Phenome Institute, State Key Laboratory of Genetic Engineering and MOE Key Laboratory of Contemporary Anthropology, Fudan University, Shanghai 200433, China.

\section{Received: 31 March 2019 Accepted: 22 December 2019}

\section{Published online: 06 January 2020}

\section{References}

1. Clegg A, Young J, lliffe S, Rikkert MO, Rockwood K. Frailty in elderly people. Lancet. 2013;381:752-62

2. Blodgett JM, Theou O, Howlett SE, Wu FC, Rockwood K. A frailty index based on laboratory deficits in community-dwelling men predicted their risk of adverse health outcomes. Age Ageing. 2016;45(4):463-8.

3. Song X, Mitnitski A, Rockwood K. Prevalence and 10-year outcomes of frailty in older adults in relation to deficit accumulation. J Am Geriatr Soc. 2010; 58(4):681-7.

4. Collard RM, Boter H, Schoevers RA, Oude Voshaar RC. Prevalence of frailty in community-dwelling older persons: a systematic review. J Am Geriatr Soc. 2012;60(8):1487-92.

5. Ng TP, Feng L, Nyunt MS, Larbi A, Yap KB. Frailty in older persons: multisystem risk factors and the frailty risk index (FRI). J Am Med Dir Assoc. 2014;15(9):635-42

6. Espinoza SE, Fried LP. Risk factors for frailty in the older adult. Clin Geriatr. 2007;15:37-44

7. Foley D, Ancoli-Israel S, Britz P, Walsh J. Sleep disturbances and chronic disease in older adults: results of the 2003 national sleep foundation sleep in America survey. J Psychosom Res. 2004;56(5):497-502. https://doi.org/10 1016/j.jpsychores.2004.02.010

8. Kurina LM, McClintock MK, Chen JH, Waite LJ, Thisted RA, Lauderdale DS Sleep duration and all-cause mortality: a critical review of measurement and associations. Ann Epidemiol. 2013;23(6):361-70. https://doi.org/10.1016/j. annepidem.2013.03.015.

9. Van Cauter E, Spiegel K, Tasali E, Leproult R. Metabolic consequences of sleep and sleep loss. Sleep Med. 2008;9(Suppl 1):S23-8. https://doi.org/10. 1016/S1389-9457(08)70013-3.

10. Gindin J, Shochat T, Chetrit A, Epstein S, Ben Israel Y, Levi S, Onder G, Carpenter I, Finne-Soveri H, van Hout H, SHELTER project, et al. Insomnia in long-term care facilities: a comparison of seven european countries and Israel: the services and health for elderly in long term care study. J Am Geriatr Soc. 2014:62(11):2033-9. https://doi.org/10.1111/jgs.13099.

11. Gildner TE, Liebert MA, Kowal P, Chatterji S, Snodgrass JJ. Associations between sleep duration, sleep quality, and cognitive test performance among older adults from six middle income countries: results from the study on global ageing and adult health (sage). J Clin Sleep Med. 2014; 10(6):613-21. https://doi.org/10.5664/jcsm.3782.

12. Maglione JE, Ancoli-Israel S, Peters KW, Paudel ML, Yaffe K, Ensrud KE, Stone KL, Study of Osteoporotic Fractures Research Group. Subjective and objective sleep disturbance and longitudinal risk of depression in a cohort of older women. Sleep. 2014;37(7):1179-87. https://doi.org/10. 5665/sleep.3834.

13. Kim J, Jo I. Age-dependent association between sleep duration and hypertension in the adult korean population. Am J Hypertens. 2010;23(12): 1286-91. https://doi.org/10.1038/ajh.2010.166.

14. Mesas AE, López-García E, León-Muñoz LM, Guallar-Castillón P, RodríguezArtalejo F. Sleep duration and mortality according to health status in older adults. J Am Geriatr Soc. 2010;58(10):1870-7. https://doi.org/10.1111/j.15325415.2010.03071.x

15. Ensrud KE, Blackwell TL, Redline S, Ancoli-Israel S, Paudel ML, Cawthon PM, Dam TT, Barrett-Connor E, Leung PC, Stone KL, Osteoporotic Fractures in Men Study Group. Sleep disturbances and frailty status in older communitydwelling men. J Am Geriatr Soc. 2009;57(11):2085-93. https://doi.org/10. 1111/j.1532-5415.2009.02490.x.

16. Del Brutto OH, Mera RM, Sedler MJ, Zambrano M, Nieves JL, Cagino K, Fanning KD, Milla-Martinez MF, Castillo PR. The effect of age in the association between frailty and poor sleep quality: a population-based study in community-dwellers (the Atahualpa project). J Am Med Dir Assoc. 2016;17(3):269-71.

17. Ensrud KE, Blackwell TL, Ancoli-Israel S, Redline S, Cawthon PM, Paudel ML, Dam $\Pi$, Stone KL. Sleep disturbances and risk of frailty and mortality in older men. Sleep Med. 2012;13(10):1217-25. https://doi.org/10.1016/..sleep. 2012.04.010

18. Nakakubo S, Makizako H, Doi T, Tsutsumimoto K, Hotta R, Lee S, Lee S, Bae S, Makino K, Suzuki T, Shimada H. Long and short sleep duration and physical frailty in community-dwelling older adults. J Nutr Health Aging. 2018;22(9):1066-71.

19. Baniak LM, Yang K, Choi J, Chasens ER. Long sleep duration is associated with increased frailty risk in older community-dwelling adults. J Aging Health. 2018. https://doi.org/10.1177/0898264318803470.

20. Kang I, Kim S, Kim BS, Yoo J, Kim M, Won CW. Sleep latency in men and sleep duration in women can be frailty markers in community-dwelling older adults: the Korean frailty and aging cohort study (KFACS). J Nutr Health Aging. 2019;23(1):63-7.

21. Liu Z, Wang Y, Zhang Y, Chu X, Wang Z, Qian D, Chen F, Xu J, Li S, Jin L, et al. Cohort profile: the Rugao Longevity and Ageing Study (RuLAS). Int J Epidemiol. 2016;45(4):1064-73. https://doi.org/10.1093/ije/dyv101.

22. Buysse DJ, Reynolds CF 3rd, Monk TH, Berman SR, Kupfer DJ. The Pittsburgh sleep quality index: a new instrument for psychiatric practice and research. Psychiatry Res. 1989;28(2):193-213.

23. Tsai PS, Wang SY, Wang MY, Su CT, Yang TT, Huang CJ, Fang SC. Psychometric evaluation of the Chinese version of the Pittsburgh sleep quality index (CPSQI) in primary insomnia and control subjects. Qual Life Res. 2005;14(8):1943-52. https://doi.org/10.1007/s11136-005-4346-x.

24. Fried LP, Tangen CM, Walston J, Newman AB, Hirsch C, Gottdiener J, Seeman T, Tracy R, Kop WJ, Burke G, Cardiovascular Health Study Collaborative Research Group, et al. Frailty in older adults: evidence for a phenotype. J Gerontol A Biol Sci Med Sci. 2001;56(3):M146-56.

25. Zhu Y, Liu Z, Wang Y, Wang Z, Shi J, Xie X, Jin L, Chu X, Wang X. Agreement between the frailty index and phenotype and their associations with falls and overnight hospitalizations. Arch Gerontol Geriatr. 2016;66:1615. https://doi.org/10.1016/j.archger.2016.06.004.

26. Liu Z, Burgess S, Wang Z, Deng W, Chu X, Cai J, Zhu Y, Shi J, Xie X, Wang Y, et al. Associations of triglyceride levels with longevity and frailty: a Mendelian randomization analysis. Sci Rep. 2017;7:41579. https://doi.org/10. 1038/srep41579

27. Zhou B, Coorperative Meta-Analysis Group Of China Obesity Task Force. Predictive values of body mass index and waist circumference to risk factors of related diseases in Chinese adult population. Zhonghua Liu Xing Bing Xue Za Zhi. 2002;23:5-10 [Article in Chinese].

28. Tsukamoto R, Akisaki T, Kuranaga M, Takata T, Yokono K, Sakurai T. Hasegawa dementia scale- revised, for screening of early Alzheimer's disease in the elderly with type 2 diabetes. Geriatr Gerontol Int. 2009;9(2): 213-5. https://doi.org/10.1111/j.1447-0594.2009.00524.x.

29. Imai $Y$, Hasegawa K. The revised Hasegawa's dementia scale (HDS-R)evaluation of its usefulness as a screening test for dementia. Hong Kong J Psychiatry. 1994;4(2):20-4.

30. Liu H, Lu X, Li C, Bai L, Dong X. Studying on relationship between Hasegawa dementia scale and nursing care of senile dementia patients. Mod Nurs. 2001;7:1-2

31. Nóbrega PV, Maciel AC, de Almeida Holanda CM, Oliveira Guerra R, Araújo JF. Sleep and frailty syndrome in elderly residents of long-stay institutions: a 
cross-sectional study. Geriatr Gerontol Int. 2014;14(3):605-12. https://doi.org/ 10.1111/ggi.12144.

32. van Oostrom $S H$, van der A DL, Rietman ML, Picavet HSJ, Lette M, Verschuren WMM, de Bruin SR, Spijkerman AMW. A four-domain approach of frailty explored in the doetinchem cohort study. BMC Geriatr. 2017;17(1): 196. https://doi.org/10.1186/s12877-017-0595-0.

33. Zhang Q, Guo H, Gu H, Zhao X. Gender-associated factors for frailty and their impact on hospitalization and mortality among community-dwelling older adults: a cross-sectional population-based study. Peer J. 2018;6:e4326. https://doi.org/10.7717/peerj.4326.

34. Morgan K, Hartescu I. Sleep duration and all-cause mortality: links to physical activity and prefrailty in a 27-year follow up of older adults in the UK. Sleep Med. 2019;54:231-7. https://doi.org/10.1016/j.sleep.2018.11.008

35. Mehra R. Failing sleep? Beware of frailty or death. Sleep Med. 2012;13(10): 1211-2. https://doi.org/10.1016/j.sleep.2012.10.001.

36. Cochen V, Arbus C, Soto ME, Villars H, Tiberge M, Montemayor T, Hein C, Veccherini MF, Onen SH, Ghorayeb I, et al. Sleep disorders and their impacts on healthy, dependent, and frail older adults. J Nutr Health Aging. 2009, 13(4):322-9.

37. Piovezan RD, Abucham J, Dos Santos RV, Mello MT, Tufik S, Poyares D. The impact of sleep on age-related sarcopenia: possible connections and clinical implications. Ageing Res Rev. 2015;23(Pt B):210-20. https://doi.org/10.1016/j. arr.2015.07.003.

\section{Publisher's Note}

Springer Nature remains neutral with regard to jurisdictional claims in published maps and institutional affiliations.

Ready to submit your research? Choose BMC and benefit from:

- fast, convenient online submission

- thorough peer review by experienced researchers in your field

- rapid publication on acceptance

- support for research data, including large and complex data types

- gold Open Access which fosters wider collaboration and increased citations

- maximum visibility for your research: over $100 \mathrm{M}$ website views per year

At BMC, research is always in progress.

Learn more biomedcentral.com/submissions 